\title{
Being in a position to know and closure: reply to Heylen
}

\author{
Sven Rosenkranz (ICREA/University of Barcelona)
}

To be upfront about it, I think that Jan Heylen's diagnosis is correct: where $\mathrm{K}$ is 'one is in a position to know' (rather than 'one knows'), the $\mathbf{K}$-axiom for $\mathrm{K}$,

$\mathbf{K}_{\mathrm{K}} \quad \mathrm{K}(\varphi \supset \psi) \supset(\mathrm{K} \varphi \supset \mathrm{K} \psi)$

fails - contrary to what I suggested in the past (Rosenkranz 2005: 52, and 2007: 77-78). For, assume that $\mathrm{K}(\varphi \supset(\psi \supset(\varphi \& \psi)))$ holds for any chosen $\varphi$ and $\psi$, as it plausibly does. Applying $\mathbf{K}_{\mathrm{K}}$ once, we get $\mathrm{K} \varphi \supset \mathrm{K}(\psi \supset(\varphi \& \psi))$. Applying $\mathbf{K}_{\mathrm{K}}$ a second time, we get $\mathrm{K} \varphi \supset(\mathrm{K} \psi \supset \mathrm{K}(\varphi \& \psi))$. We can thus derive

$$
\mathrm{K} \varphi \& \mathrm{~K} \psi \supset \mathrm{K}(\varphi \& \psi)
$$

according to which $\mathrm{K}$ agglomerates over conjunction. However, (1) fails. Let $\kappa$ be 'one knows'. Uncontroversially, $\kappa \varphi$ implies 'Someone sometimes knows $\varphi$ ', and $\kappa$ validates

$$
\begin{aligned}
& \kappa \varphi \supset \varphi \\
& \kappa(\varphi \& \psi) \supset \kappa \varphi
\end{aligned}
$$

Now let $\psi$ be 'No one ever knows $\varphi$ '; then $\neg \backslash \kappa(\varphi \& \psi)$ follows (Fitch 1963). Plausibly, however, if $\mathrm{K} \varphi$ holds, so does $\diamond_{\kappa} \varphi{ }^{1}{ }^{1}$ Hence, $\neg \mathrm{K}(\varphi \& \psi)$ follows. (1) would accordingly imply $\neg(\mathrm{K} \varphi \& \mathrm{~K} \psi)$. And yet, where $\psi$ is 'No one ever knows $\varphi$ ', there are $\varphi$ for which this conclusion would seem clearly unacceptable. Thus let $\varphi$ be a fleeting truth of little interest, e.g. 'There are at present exactly seven blossoms on the bougainvillea', in a context where the plant is in full view, a storm is about to hit, one is the only one around, the latter facts are known, and one also knows by introspection - and a fortiori is in a position to know - that one is far too unconcerned ever to find out about the matter. In such a case, both $\mathrm{K} \varphi$ and $\mathrm{K} \psi$ should hold, contrary to what (1) predicts - at least there would seem to be nothing inherent in the notion of being in a position to know that would preclude this. ${ }^{2}$ Therefore, (1) fails, and hence so does $\mathbf{K}_{\mathrm{K}}$.

The case generalises to propositional justification. Let $\mathrm{J}$ be 'is justified'. Plausibly, the following principles both hold

(5) $\mathrm{J} \varphi \supset \neg \mathrm{K} \neg \mathrm{K} \varphi$

\footnotetext{
${ }^{1}$ Perhaps the case is not so straightforward, given that both $\mathrm{K}$ and $\kappa$ are tensed. Suppose that one is in a position to know $\varphi$, but that coming to know $\varphi$ takes some time. Arguably, it does not then follow that one could presently know that $\varphi$ holds. This suggestive thought depends on a particular conception of how modal and temporal operators interact. In any case, however, here it is enough to presuppose that $\mathrm{K} \varphi$ at least implies 'Possibly, one sometimes knows $\varphi$ ', for given the intended interpretation of $\psi$, the argument is equally suited to show that it is impossible that one ever knows ( $\varphi \& \psi)$.

${ }^{2}$ We certainly do not want to say that the mere fact that one never knows $\varphi$ 'blocks one's path to knowing' $\varphi$ (Williamson 2000: 95); for otherwise $\mathrm{K} \varphi$ would collapse into 'One sometimes knows $\varphi$ '.
} 
(cf. Schaffer 2007: 235; Williamson 2000: 255-56; Smithies 2012: 738; Rosenkranz unpublished). Equally plausibly, $\mathrm{J}(\varphi \supset(\psi \supset(\varphi \& \psi)))$ holds, for any chosen $\varphi$ and $\psi$. So if, in addition, we had the $\mathbf{K}$-axiom for $\mathbf{J}$,

$\mathbf{K}_{\mathrm{J}} \quad \mathrm{J}(\varphi \supset \psi) \supset(\mathrm{J} \varphi \supset \mathrm{J} \psi)$

we could infer that $\mathrm{J}$ agglomerates over conjunction, i.e.

$$
\mathrm{J} \varphi \& \mathrm{~J} \psi \supset \mathrm{J}(\varphi \& \psi)
$$

We have already seen that if $\psi$ is 'No one ever knows $\varphi$ ', $\neg \mathrm{K}(\varphi \& \psi)$ can be derived. Being readily available, the derivation puts one in a position to know its result, whence we obtain $\mathrm{K} \neg \mathrm{K}(\varphi \& \psi)$. By (5), this yields $\neg \mathrm{J}(\varphi \& \psi)$. Considering again the case of the bougainvillea, with $\varphi$ and $\psi$ interpreted accordingly, we nonetheless get from $\mathrm{K} \varphi, \mathrm{K} \psi$ and (4) that both $\mathrm{J} \varphi$ and J $\psi$ hold. Accordingly, (6) fails for the same sort of reason for which (1) fails, and hence so does $\mathbf{K}_{\mathrm{J}}{ }^{3}$ Thus, we do not have to opt for a probabilistic reading of $\mathbf{J}$ in order to find fault with (6).

The logics for $\mathrm{K}$ and $\mathrm{J}$ cannot, thence, be normal modal logics. Does it follow that the principle

$$
\mathrm{K} \varphi \supset \mathrm{K} \neg \mathrm{K} \neg \varphi
$$

cannot be derived? Not necessarily. Like $\kappa, \mathrm{K}$ is supposed to be factive (Williamson 2000: 95; cf. also Rosenkranz 2005 and 2007). Thus, the T-axiom for K,

$\mathbf{T}_{\mathrm{K}} \quad \mathrm{K} \varphi \supset \varphi$

holds. Accordingly, $\varphi \supset \neg \mathrm{K} \neg \varphi$ is a theorem. If we also have the rule

$\mathbf{R M}_{\mathrm{K}} \quad$ If $\mid-\varphi \supset \psi$, then $\mid-\mathrm{K} \varphi \supset \mathrm{K} \psi$

then (7) follows. $\mathbf{R} \mathbf{M}_{\mathrm{K}}$ may hold, even if $\mathbf{K}_{\mathrm{K}}$ fails. The above counterexample to $\mathbf{K}_{\mathrm{K}}$ is a counterexample to (1). It employs a pair of propositions, $\varphi$ and $\psi$, such that $\psi \supset(\varphi \quad \& \quad \psi)$ is not a theorem. Since we accordingly cannot derive $\mathrm{K} \varphi \supset(\mathrm{K} \psi \supset \mathrm{K}(\varphi \& \psi))$ from $\mathrm{K} \varphi \supset \mathrm{K}(\psi \supset(\varphi \& \psi))$ by $\mathbf{R} \mathbf{M}_{\mathrm{K}}$ alone, $\mathbf{R} \mathbf{M}_{\mathrm{K}}$ is unaffected by the example.

$\mathbf{R M}_{\mathrm{K}}$ involves a hefty idealisation, since it may be unobvious what follows from what. But note that the same worry afflicts the principle of closure that Heylen attributes to Schaffer (2007: 235) and that Heylen does nothing to challenge. The principle is

$$
(\kappa \varphi \&(\varphi \rightarrow \psi)) \rightarrow \mathrm{K} \psi
$$

where $\rightarrow$ expresses entailment. ${ }^{4}(\mathrm{~S})$ is weaker than $\mathbf{R} \mathbf{M}_{\mathrm{K}}$, since the latter implies

$$
(\mathrm{K} \varphi \&(\varphi \rightarrow \psi)) \rightarrow \mathrm{K} \psi
$$

\footnotetext{
${ }^{3}$ This also negatively affects part of what I said in Rosenkranz (2007: 81).

${ }^{4}$ In the published version of Schaffer's text, the statement of the principle is corrupted, but the context makes clear that only an ' $\&$ ' is missing (Schaffer 2007: 235). (Note that Schaffer uses ' $K$ ' for 'one knows' rather than 'one is in a position to know'.)
} 
(at least assuming that $\rightarrow$ expresses logical entailment and $\mathbf{R} \mathbf{M}_{\mathrm{K}}$ has the status of a rule of epistemic logic). However, pending further argument, I fail to see that this difference in strength matters. What does matter is that $(S)$ involves the very same idealisation. For, if someone knows $\varphi$ but is in no position to figure out that $\varphi$ entails $\psi$, why should it nonetheless follow that they are in a position to know $\psi$ ? Since $\mathrm{K} \varphi$ does not entail $\kappa \varphi$, the idealisation involved in $\mathbf{R} \mathbf{M}_{\mathrm{K}}$ and (S) is weaker than any idealisation that would require subjects to be logically omniscient. It is an idealisation nonetheless. In general, it is difficult to see how epistemic logic can get off the ground without making idealisations of any kind. But perhaps the idealisation in question is still deemed unacceptable, even if other idealisations may not be (cf. Williamson 1993). For this reason, we might want to replace $\mathbf{R} \mathbf{M}_{\mathrm{K}}$ by the weaker rule

$$
\mathbf{R M}_{\mathrm{K}}^{*} \text { If } \mid-\varphi \supset \psi \text {, then } \mid-\mathrm{K}(\varphi \supset \psi) \supset(\mathrm{K} \varphi \supset \mathrm{K} \psi)^{5}
$$

Unlike $\mathbf{R} \mathbf{M}_{\mathrm{K}}, \mathbf{R} \mathbf{M}_{\mathrm{K}}$ * does not require that subjects are always in a position to know everything logically entailed by what they are in a position to know. It merely requires that subjects be in that position if they are furthermore in a position to acknowledge the corresponding implication. ${ }^{6}$

The original derivation of (7) in Rosenkranz (2005) and (2007) anyway presupposes that $\mathrm{K}(\varphi \supset \neg \mathrm{K} \neg \varphi)$ holds. Under the same presupposition, and given $\mathbf{T}_{\mathrm{K}}$, (7) is already derivable by means of $\mathbf{R} \mathbf{M}_{\mathrm{K}}{ }^{*}$. Again, since the above counterexample to $\mathbf{K}_{\mathrm{K}}$ employs a pair of propositions, $\varphi$ and $\psi$, such that $\psi \supset(\varphi \& \psi)$ is not a theorem, we cannot derive $\mathrm{K} \varphi \supset(\mathrm{K} \psi \supset \mathrm{K}(\varphi \& \psi))$ from $\mathrm{K} \varphi \supset \mathrm{K}(\psi \supset(\varphi \& \psi))$ by $\mathbf{R M}_{\mathrm{K}}{ }^{*}$ alone. Therefore, $\mathbf{R M}_{\mathrm{K}}{ }^{*}$ is unaffected by the example. Pending further argument to the contrary, as a rule of epistemic closure $\mathbf{R} \mathbf{M}_{\mathrm{K}}$ * looks rather promising, even if it may not be altogether free of idealisations either. ${ }^{7}$

In Rosenkranz (2005) I use (7) to show why the account of borderline cases given by Wright (2004) founders. In Rosenkranz (2007: 84) I use (7) to render plausible why 'anyone who claims to know $p$ is bound to argue that anyone who claims to know $\neg p$ does not achieve what he aims to achieve, and vice versa' - thereby motivating a notion of opposition that also captures the contrast between believers and agnostics. ${ }^{8}$ I likewise

\footnotetext{
${ }^{5}$ If we also had the rule of necessitation

$\mathbf{R N}_{\mathrm{K}} \quad$ If $\mid-\varphi$, then $\mid-\mathrm{K} \varphi$

$\mathbf{R} \mathbf{M}_{\mathrm{K}}$ and $\mathbf{R} \mathbf{M}_{\mathrm{K}}$ * would be interderivable. But, evidently, $\mathbf{R} \mathbf{N}_{\mathrm{K}}$ requires at least as strong an idealisation as $\mathbf{R M}_{\mathrm{K}}$.

${ }^{6}$ It is unclear why Schaffer (2007) opts for (S) rather than $(\kappa \varphi \& \varphi \rightarrow \psi) \rightarrow(\mathrm{K}(\varphi \supset \psi) \supset \mathrm{K} \psi)$.

${ }^{7} \mathbf{R} \mathbf{M}_{\mathrm{K}}$ * would seem to presuppose that, where $\varphi$ logically entails $\psi$, and both $\mathrm{K}(\varphi \supset \psi)$ and $\mathrm{K} \varphi$ hold, knowing $\varphi$ never precludes knowing $\varphi \supset \psi$, nor vice versa. This presupposition is not trivial. Thus, let $\varphi$ be 'One knows no logical truth' and let $\psi$ be 'One knows no logical truth or the moon is made of cheese'; then knowing $\varphi$ precludes knowing $\varphi \supset \psi$, because $\varphi$ already does. However, even someone who knew no logical truth, and was in a position to know this much about themselves, could still be in a position to know some logical truth. Thus $\mathrm{K} \varphi$ is consistent with $\mathrm{K}(\varphi \supset \psi)$. And yet, $\mathrm{K} \psi$ would seem to fail, since there would seem to be no other way of knowing $\psi$ save on the basis of knowing both $\varphi$ and $\varphi \supset \psi$. Here it is being assumed that $\varphi$ is true, and hence that the subject knows no logical truth. That $\varphi$ and its ilk fail to be true of subjects to which epistemic logic applies strikes me as a rather harmless idealisation. It remains to be seen whether there are less outré problem cases that put pressure on $\mathbf{R} \mathbf{M}_{\mathrm{K}}{ }^{*}$.

8 The phrase 'claims to know' does not here refer to second-order claims to the effect that one knows a given proposition, but to attempts to qualify as knowing what one believes. Given that '[a]nyone who presents himself as someone who can truly be described as knowing $p$ is under the obligation to do whatever it takes to earn that title', (7) delivers the desired result (Rosenkranz 2007: 79-81).
} 
use (7) to argue that anyone who aspires to knowledge of what they claim cannot coherently claim $\neg \mathrm{K} \neg \mathrm{K} \varphi$ \& $\neg \mathrm{K} \neg \mathrm{K} \neg \varphi$, because the latter both implies $\neg \mathrm{K} \varphi$ \& $\neg \mathrm{K} \neg \varphi$ and precludes $K(\neg K \varphi \& \neg K \neg \varphi)$ (2007: 85, 87). Since as shown, (7) need not rely on either $\mathbf{K}_{\mathrm{K}}$ or (1), these results are equally independent from $\mathbf{K}_{\mathrm{K}}$ and (1). ${ }^{9}$

I also use $\mathbf{K}_{\mathrm{K}}$ in order to argue that $\mathrm{K}(\neg \mathrm{K} \varphi \supset \mathrm{K} \neg \mathrm{K} \varphi)$ implies $\mathrm{K} \varphi \supset \mathrm{KK} \varphi$ (2007: 86n), and that $\neg \mathrm{K} \diamond \mathrm{K} \varphi$ implies $\neg \mathrm{KK} \varphi$ (2007: 90). In the dialectical context in which the former result is presented, it can also be assumed, for argument's sake alone, that $\neg \mathrm{K} \varphi \supset \mathrm{K} \neg \mathrm{K} \varphi$ has the status of a theorem. Since $\mathrm{K} \varphi \supset \diamond \mathrm{K} \varphi$ is a theorem that we are in a position to know, both results can accordingly be obtained using $\mathbf{R} \mathbf{M}_{\mathrm{K}}$ or $\mathbf{R} \mathbf{M}_{\mathrm{K}}{ }^{*}$ instead of $\mathbf{K}_{\mathrm{K}}$.

Lastly, I use (1) in order to show that $\neg \mathrm{K} \varphi \supset \mathrm{K} \neg \mathrm{K} \varphi$ implies $\neg \mathrm{K}(\neg \mathrm{K} \varphi \& \neg \mathrm{K} \neg \varphi) \supset$ $(\mathrm{K} \varphi \vee \mathrm{K} \neg \varphi)$ (2007: 85-86), and that one cannot have justification for holding both $\neg \mathrm{K} \varphi$ and $\neg \mathrm{K} \neg \mathrm{K} \varphi$ (2007: 88). Without (1), the former argument clearly founders; but since it is merely offered on behalf of a position that is ultimately rejected for independent reasons, this mistake is not detrimental. By contrast, the latter result can easily be obtained without appeal to (1). Given that one is always in a position to know that conjunctions imply their conjuncts, by $\mathbf{T}_{\mathrm{K}}$ and either one of $\mathbf{R} \mathbf{M}_{\mathrm{K}}$ and $\mathbf{R} \mathbf{M}_{\mathrm{K}}{ }^{*}$, we get $\neg \mathrm{K}(\neg \mathrm{K} \varphi$ \& $\neg \mathrm{K} \neg \mathrm{K} \varphi)$. Since this piece of reasoning is always available, $\mathrm{K} \neg \mathrm{K}(\neg \mathrm{K} \varphi$ \& $\neg \mathrm{K} \neg \mathrm{K} \varphi)$ holds. By (5), $\neg \mathrm{J}(\neg \mathrm{K} \varphi$ \& $\neg \mathrm{K} \neg \mathrm{K} \varphi)$ follows.

To conclude: I concur with Heylen that it is mistaken to assume $\mathbf{K}_{\mathrm{K}}$, where $\mathrm{K}$ is 'one is in a position to know', and hence equally mistaken to use $\mathbf{K}_{\mathrm{K}}$ in deriving (7) - mistakes I made in the past. However, given that $\mathrm{K}$ is known to be factive, (7) can be derived using $\mathbf{R} \mathbf{M}_{\mathrm{K}}$ or $\mathbf{R} \mathbf{M}_{\mathrm{K}}{ }^{*}$ instead, with the latter being rather plausible; and given either one of these rules, the main points made in Rosenkranz (2005) and (2007) survive. ${ }^{10}$

\section{References}

Fitch, F. B. 1963: 'A Logical Analysis of Some Value Concepts', The Journal of Symbolic Logic 28, 135-142.

Heylen, J. 2016: 'Being in a position to know and closure', Thought, this issue.

Rosenkranz, S. 2005: 'Knowledge in borderline case', Analysis 65, 49-55.

Rosenkranz, S. 2007: 'Agnosticism as a Third Stance', Mind 116, 55-104.

Rosenkranz, S. unpublished: 'The Structure of Justification', ms.

Schaffer, J. 2007: 'Closure, Contrast, and Answer', Philosophical Studies 133, 233-55.

Smithies, D. 2012: 'Mentalism and Epistemic Transparency', Australasian Journal of Philosophy 90, 723-41.

Williamson, T. 1993: 'Some Admissible Rules in Nonnormal Modal Systems', Notre Dame Journal of Formal Logic 34, 378-400.

Williamson, T. 2000: Knowledge and Its Limits, Oxford: Oxford University Press.

Wright, C. 2004: 'Vagueness: a fifth column approach', in Beall and Glanzberg (eds.), Liars and Heaps: New Essays on Paradox, Oxford: Oxford University Press, 84-105.

\footnotetext{
${ }^{9}$ That K distributes over conjunction follows from $\mathbf{R} \mathbf{M}_{\mathrm{K}}$ and also from $\mathbf{R} \mathbf{M}_{\mathrm{K}}{ }^{*}$, given the plausible further assumption that one is always in a position to know that conjunctions imply their conjuncts.

${ }^{10} \mathrm{I}$ am grateful to Fabrice Correia, Esa Díaz León, Kit Fine, Patrick Greenough, Jan Heylen, Tim Kraft, José Martínez, Aidan McGlynn, Ramon Jansana, Casey Perin, Hans Rott, Moritz Schulz, Christian Wirrwitz and Crispin Wright for helpful discussions in the context of my work on Rosenkranz (unpublished) that prepared the grounds for this reply. I also like to thank the editors of Thought for their kind invitation to respond to Heylen's article. Work on this paper received funding from the project FFI2013-45968-P, financed by the Spanish Ministry for Economy and Competition (MINECO).
} 